\title{
CONTROL DE LA MADURACIÓN EN FRUTOS DE PAPAYA (Carica papaya L.) CON 1-METILCICLOPROPENO Y ÁCIDO 2-CLOROETIL FOSFÓNICO
}

\author{
RIPENING CONTROL OF PAPAYA (Carica papaya L.) FRUITS WITH \\ 1-METHYLCYCLOPROPENE AND 2-CHLOROETHYL PHOSPHONIC ACID
}

\author{
J. Adriana Sañudo Barajas ${ }^{1}$, Jorge Siller Cepeda ${ }^{1 *}$, Tomás Osuna Enciso ${ }^{1}$, Dolores Muy Rangel ${ }^{1}$, \\ Guadalupe López Álvarez² y John Labavitch ${ }^{3}$
}

\footnotetext{
${ }^{1}$ Centro de Investigación en Alimentación y Desarrollo, A. C. Unidad Culiacán. Apdo. postal 32-A. 80129, Culiacán, Sinaloa. México. ${ }^{2}$ Instituto Tecnológico de Culiacán, Sinaloa, México. ${ }^{3}$ Plant Reproductive Biology, University of California, Davis, Ca. USA.

*Autor para correspondencia (jsiller@ciad.edu.mx)
}

\section{RESUMEN}

Con el objetivo de encontrar una estrategia efectiva para controlar la maduración de papaya (Carica papaya L. cv. 'Maradol'), se evaluó la respuesta de los frutos a la aplicación de $300 \mathrm{~nL} \mathrm{~L}^{-1}$ del inhibidor 1-metilciclopropeno (1-MCP) y de $2.5 \mathrm{~g} \mathrm{~L}^{-1}$ del inductor ácido 2-cloroetil fosfónico (etefón). A frutos cosechados en estado de madurez 1/4 se les aplicaron los tratamientos: testigo, 1-MCP, etefón, 1MCP+etefón y etefón+1-MCP; en los tratamientos combinados, la aplicación del segundo compuesto fue después de $24 \mathrm{~h}$ del primer tratamiento. Los frutos se mantuvieron almacenados en condiciones de simulación de mercadeo y se evaluó la calidad postcosecha durante 9 d. El tratamiento con 1-MCP inhibió la producción de etileno y el ablandamiento de los frutos, y disminuyó significativamente la tasa respiratoria, el color en cáscara y pulpa, y el contenido de ácidos orgánicos. El etefón aceleró los cambios en color y produjo una pérdida de $80 \%$ en la firmeza inicial de los frutos a los $3 \mathrm{~d}$ de la aplicación. Los frutos del tratamiento 1-MCP+etefón no perdieron la firmeza, lo que sugiere que la acción del 1-MCP en suprimir el ablandamiento fue irreversible. Una alternativa para controlar la maduración de papaya 'Maradol' fue el tratamiento etefón+1-MCP, ya que la aplicación posterior de 1-MCP redujo los cambios en maduración inducidos por etefón.

Palabras clave: Carica papaya, 1-MCP, etefón, etileno, maduración, ablandamiento.

\section{SUMMARY}

In order to find an effective strategy to control papaya (Carica papaya L. cv. 'Maradol') ripening, fruit responses to the application of $300 \mathrm{~nL} \mathrm{~L}^{-1}$ of the inhibitor 1-methylcyclopropene (1-MCP) and 2.5 $\mathrm{g} \mathrm{L}^{-1}$ of the inducer 2-chloroethyl phosphonic acid (ethephon) were evaluated. Fruits harvested at 1/4 ripening stage were treated with: control, 1-MCP, ethephon, 1-MCP+ethephon and ethephon+1MCP; in combined treatments, the second compound was applied 24 $h$ after the first treatment. Fruits were stored in simulated marketing conditions and postharvest quality was evaluated during 9 d. 1-MCP treatment inhibited ethylene production and fruit softening, decreased significantly the respiratory rate, color development in peel and flesh, and the content of organic acids in fruits. Three days after application, ethephon accelerated color changes and caused a loss of $80 \%$ on fruit firmness. Fruits of the treatment 1-MCP+ethephon did not lose firmness, thus suggesting that 1-MCP's action in suppressing fruit softening was irreversible. An alternative to control papaya 'Maradol' ripening was the treatment ethephon $+1-M C P$, since the 1MCP application delayed the ripening changes induced by ethephon.

Index words: Carica papaya, 1-MCP, ethephon, ethylene, ripening, softening.

\section{INTRODUCCIÓN}

En los Estados de Veracruz y Chiapas se concentra más de $50 \%$ de la superficie destinada a la producción de papaya en México, donde la variedad 'Maradol' ocupa la mayor superficie y volumen exportado (SAGARPA, 2006). Esta variedad es de pulpa roja, color que se atribuye a la presencia de criptoxantina $\beta$, licopeno y caroteno $\zeta$ y $\beta$ (Chandrika et al., 2003). La papaya es un fruto climatérico de corta vida de anaquel que se cosecha en madurez fisiológica para extender su periodo de comercialización. Esta madurez se identifica por un color amarillo-naranja en $1 / 4$ de la superficie del fruto; la pulpa es firme pero el sabor aún no es aceptable para consumo; además, el fruto produce etileno e incrementa la sensibilidad al etileno exógeno (Quintana y Paull, 1993; Paull et al., 1997).

El etileno regula cambios en composición y estructura durante la maduración del fruto, como disminución del contenido de clorofila (Urbano et al., 2004), incremento de carotenoides (Chandrika et al., 2003), liberación de volátiles (Pino et al., 2003) e hidrólisis de pectinas y hemicelulosas (Paull et al., 1999). El ablandamiento del fruto de papaya, derivado de la acción de hidrolasas inducidas por etileno, es un factor de calidad difícil de controlar durante postcosecha (Thumdee et al., 2007). Este ablandamiento progresa del endocarpio hacia la epidermis y la falta de uniformidad restringe su comercialización a corto plazo, 
por lo que generalmente el fruto se expone al gaseo con etileno exógeno para uniformar la maduración, aunque ello acorta su vida útil (Paull et al., 1997).

En frutos de papaya 'Solo', el almacenamiento a bajas temperaturas y el uso del inhibidor de maduración 1Metilciclopropeno (1-MCP) son estrategias que controlan la acción y la producción de etileno (Hofman et al., 2001). El 1-MCP es un inhibidor del etileno que reduce el deterioro de frutas y hortalizas, al competir por el sitio de unión del etileno a sus receptores de membrana y bloquear la activación de los procesos metabólicos que se regulan por esta vía de percepción hormonal (Blankenship y Dole, 2003). El 1-MCP disminuye principalmente el ablandamiento y la producción de etileno; sin embargo, esto depende del tipo de fruto y del estado de madurez, así como de la concentración, tiempo y temperatura de exposición. Según Hoeberichts et al. (2002), la acción del 1-MCP es irreversible y la acción del etileno se recupera mediante la síntesis de nuevos receptores.

En papaya, el 1-MCP inhibe el ablandamiento, lo cual se ha asociado con una capacidad lenta del fruto para regenerar receptores de etileno (Hofman et al., 2001). La efectividad del 1-MCP para bloquear la acción del etileno endógeno en papaya se encuentra definida, pero se desconoce su efectividad para inhibir al etileno exógeno. En el presente trabajo se estudió la respuesta de frutos de papaya 'Maradol' a la aplicación sola y combinada de 1-MCP y etefón, con el propósito de encontrar alternativas de manejo postcosecha que permitan controlar la velocidad de maduración y extender la vida útil.

\section{MATERIALES Y MÉTODOS}

En Junio del 2006 se cosecharon frutos de papaya 'Maradol' en madurez de $1 / 4$ (color amarillo-naranja en $25 \%$ de la cáscara) en un huerto comercial de Tepic, Nayarit, México. Se seleccionaron frutos de tamaño homogéneo, sin daños mecánicos y sin plagas ni enfermedades, y se desinfectaron en una solución de Captán $\left(2.5 \mathrm{~g} \mathrm{~L}^{-1}\right)$. Los frutos se dividieron en cinco lotes de 50 a los que se aplicaron los siguientes tratamientos: No tratado (testigo); 300 $\mathrm{nL} \mathrm{L}^{-1}$ de 1-MCP; $2.5 \mathrm{~g} \mathrm{~L}^{-1}$ de ácido 2-cloroetil fosfónico (etefón); $300 \mathrm{~nL} \mathrm{~L}^{-1}$ de $1-\mathrm{MCP}+2.5 \mathrm{~g} \mathrm{~L}^{-1}$ de etefón (1$\mathrm{MCP}+$ etefón); y $2.5 \mathrm{~g} \mathrm{~L}^{-1}$ de etefón $+300 \mathrm{~nL} \mathrm{~L}^{-1}$ de 1$\mathrm{MCP}$ (etefón+1-MCP). Para la aplicación del 1-MCP, se colocaron 100 frutos en contenedores de acero inoxidable herméticamente cerrados $\left(\mathrm{de} 0.238 \mathrm{~m}^{3}\right.$ ) y se liberaron 300 $\mathrm{nL} \mathrm{L}^{-1}$ de 1-MCP (SmartFresh ${ }^{\circledR}$ ) para una exposición de $12 \mathrm{~h}$ a $20^{\circ} \mathrm{C}$. Para la inducción de maduración, se sumergieron 100 frutos durante 3 min en una solución (a $20^{\circ} \mathrm{C}$ ) de $2.5 \mathrm{~g} \mathrm{~L}^{-1}$ de etefón (Madurex ${ }^{\circledR}$ ). Después de $24 \mathrm{~h}$ de aplicado el 1-MCP o el etefón, los 50 frutos de cada tra- tamiento fueron tratados con el antagónico respectivo en los tratamientos combinados. Finalmente, los frutos se almacenaron a temperatura controlada en condiciones de simulación de mercadeo $\left(20 \pm 2{ }^{\circ} \mathrm{C}\right.$ y $\left.85 \pm 2 \% \mathrm{HR}\right)$.

\section{Producción de $\mathrm{CO}_{2}$ y etileno}

Se seleccionaron tres frutos por tratamiento y cada fruto se colocó en un frasco de vidrio con tapa de goma conectada con una manguera de entrada continua de aire libre de $\mathrm{CO}_{2}$ y una de salida. Diariamente se registró el flujo de aire en la manguera de salida con un medidor de flujo digital (Varian Inc.) y se extrajo $1 \mathrm{~mL}$ de gas de la atmósfera interior del frasco, la cual se inyectó a un cromatógrafo de gases Varian 3300 (Varian Inc.), equipado con una columna Hayesep Q 100/120 (1.8 m longitud x 3.2 mm diámetro) y dos detectores en serie; uno de conductividad térmica (TCD) para la cuantificación de $\mathrm{CO}_{2}$, y uno de ionización de flama (FID) para la detección de etileno. Se utilizó helio como gas acarreador con un flujo de $25 \mathrm{~mL} \mathrm{~min}^{-1}$. Las condiciones de temperatura para cada corrida se mantuvieron a $70{ }^{\circ} \mathrm{C}$ para la columna, $100{ }^{\circ} \mathrm{C}$ para el inyector, $120{ }^{\circ} \mathrm{C}$ para el detector TCD y $170{ }^{\circ} \mathrm{C}$ para el detector FID (Báez et al., 1997). Los resultados se calcularon a partir de curvas de calibración con estándares de concentración conocida de $\mathrm{CO}_{2}$ y $\mathrm{C}_{2} \mathrm{H}_{4}$ (Linde Gas LLC).

\section{Firmeza y color interno}

Se utilizaron tres frutos por tratamiento para medir ambas variables. La firmeza se midió por el método de punción con un penetrómetro digital Chatillón DFGS-100 provisto con punzón de $8 \mathrm{~mm}$ de diámetro y base automática TCD 200 (Chatillon). Se registró la fuerza de oposición del tejido a la penetración del punzón, insertado a una velocidad de $5.3 \mathrm{~mm} \mathrm{~s}^{-1}$ en cuatro regiones del fruto; los resultados se reportaron en newtons (N) (Bourne, 1980). Posteriormente, los frutos se cortaron longitudinalmente y se determinó el color interno en cuatro regiones del mesocarpo, con un espectrofotómetro Konica CM-2600d (Minolta Inc.) que permitió medir la luminosidad (L), ángulo de matiz (Hue) y cromaticidad (croma) con el programa OnColor QC versión 5. Los frutos cortados se utilizaron para medir el $\mathrm{pH}$, la acidez titulable y los sólidos solubles totales.

\section{pH, acidez titulable y sólidos solubles totales}

Para estas determinaciones se utilizó el método de la AOAC (1998) con algunas modificaciones, en tejido de frutos cortados anteriormente. Se licuaron $10 \mathrm{~g}$ de fruto parcialmente descongelado y $50 \mathrm{~mL}$ de agua destilada; la mezcla se filtró en tela organza y se utilizaron $50 \mathrm{~mL}$ del filtrado para cuantificar el $\mathrm{pH}$ y la acidez titulable (AT) 
con un titulador automático (Mettler Toledo Mod. DL-50). La AT se expresó como porcentaje de ácido málico. Del residuo del filtrado se determinó el contenido de sólidos solubles totales en un refractómetro (Mettler Toledo Mod. RE40D) con compensación de temperatura a $20{ }^{\circ} \mathrm{C}$ y los resultados se expresaron en ${ }^{\circ}$ Brix.

\section{Color en cáscara}

Se seleccionaron cinco frutos por tratamiento y en cuatro puntos equidistantes de la superficie se midió el color con un espectrofotómetro Konica CM-2600d (Minolta Inc.) y se registraron los valores de L, Hue y croma con el programa OnColor QC versión 5.

\section{Análisis estadísticos}

Se usó un diseño completamente al azar de dos factores; el factor tratamiento con cinco niveles (testigo, 1$\mathrm{MCP}$, etefón, 1-MCP + etefón y etefón+1-MCP), y el factor tiempo de almacenamiento con cuatro niveles $(0,3,6 \mathrm{y}$ 9 d). Se hizó una prueba de ANOVA con el paquete estadístico Minitab 14; en caso de valores $\mathrm{P} \leq 0.05$ en la prueba de F, se compararon las medias con la prueba de Tukey $(\alpha=0.05)$.

\section{RESULTADOS Y DISCUSIÓN}

\section{Producción de $\mathrm{CO}_{2}$ y etileno}

El máximo incremento en la producción de $\mathrm{CO}_{2}$, generalmente definido como pico climatérico, se detectó a los 4 $\mathrm{d}$ en los frutos testigo, etefón y 1-MCP+etefón (Figura 1A). No se observó adelanto o retraso en la aparición de este pico en respuesta al etileno o al 1-MCP, como fue mostrado en plátano (Musa paradisiaca) y tomate (Lycopersicon esculentum) (Golding et al., 1998; Hoeberichts et al., 2002).

La tasa de respiración en los frutos testigo de papaya 'Maradol', fue similar a la reportada en papaya 'Solo' (Paull et al., 1997). En otros frutos tropicales, la aplicación de 1-MCP disminuyó la tasa de respiración, similar a lo observado en el presente trabajo (Hofman et al., 2001). La tasa respiratoria promedio fue significativamente mayor en los frutos testigo, etefón y etefón+1-MCP $(18.3,18$ y $17 \mathrm{~mL} \mathrm{CO}_{2} \mathrm{~kg}^{-1} \mathrm{~h}^{-1}$ ), seguidos por los frutos del tratamiento $1-\mathrm{MCP}+$ etefón que presentaron valores intermedios (12.3 mL CO $2 \mathrm{~kg}^{-1} \mathrm{~h}^{-1}$ ), y finalmente de los frutos con 1$\mathrm{MCP}$ con la tasa de respiración más baja $\left(8.9 \mathrm{~mL} \mathrm{CO} \mathrm{kg}^{-1}\right.$ $\mathrm{h}^{-1}$ ). Lo anterior sugiere que la acción que ejerce el etileno en la tasa respiratoria de los frutos no se reduce con la aplicación de 1-MCP, y que la disminución que produce el inhibidor puede reactivarse parcialmente con la aplicación de etileno exógeno.

La tasa de producción de etileno en los frutos de papaya 'Maradol' fue baja en comparación con los 6 a $8.6 \mu \mathrm{L}$ $\mathrm{kg}^{-1} \mathrm{~h}^{-1}$ reportados para la papaya 'Solo' (Paull et al. 1997). La producción de etileno mostró diferencias significativas entre tratamientos en el tiempo de aparición y en la magnitud del máximo valor (Figura 1B). La aplicación de etefón adelantó la aparición del pico máximo (día 3) en comparación con el testigo (día 7), similar a lo observado por Paull et al. (1997). Por el contrario, los frutos tratados con 1-MCP retrasaron y redujeron significativamente la producción de etileno al compararlos con los otros tratamientos (Figura 1B), resultado que es similar a lo reportado por Hofman et al.(2001).
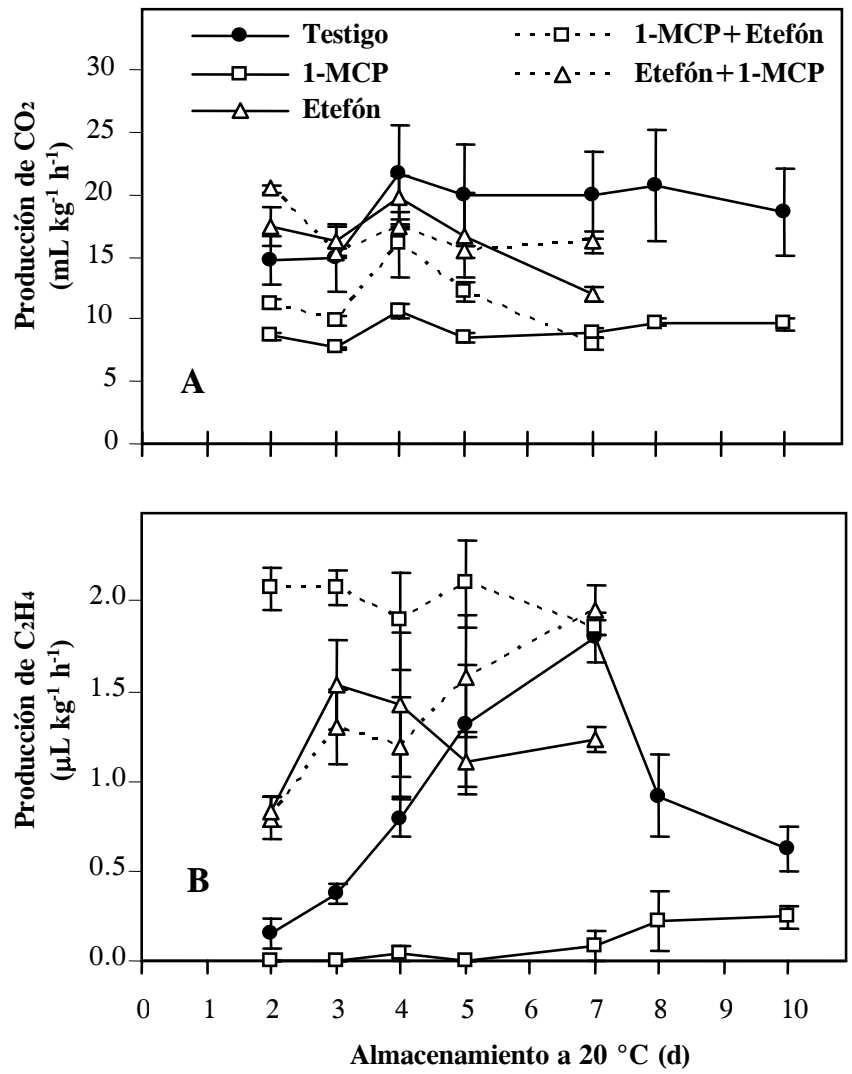

Figura 1. Actividad fisiológica de papaya 'Maradol' tratada con 1MCP, etefón, 1-MCP+etefón y etefón+1-MCP. A) Tasa de producción de bióxido de carbono en $\mathrm{mL} \mathrm{kg}^{-1} \mathrm{~h}^{-1}$. B) Tasa de producción de etileno en $\mu \mathrm{L} \mathrm{kg}^{-1} \mathrm{~h}^{-1}$. La barra vertical representa el error estándar $(\mathbf{n}=3)$.

La detección de etileno en los frutos con 1$\mathrm{MCP}+$ etefón podría indicar la posible activación de la biosíntesis de etileno por efecto del etefón, o bien la acumulación de etileno exógeno producto de la hidrólisis del etefón; sin embargo, la inhibición del ablandamiento y el retraso de color en cáscara observado en los frutos de este 
tratamiento, mostraron que el 1-MCP actuó como inhibidor de la acción del etileno. En frutos de plátano, la aplicación de 1-MCP en pre-climaterio inhibió la producción de etileno, lo que no ocurrió cuando la aplicación se hizo una vez iniciada la maduración (Golding et al., 1998; Inaba et al., 2007).

\section{Firmeza}

La firmeza inicial de los frutos de papaya 'Maradol' cosechados en el estado de madurez $1 / 4$ (verde con rayas amarillas) presentó valores de $\approx 144 \pm 5 \mathrm{~N}$ (Figura 2), valor que los caracteriza como frutos en estado de madurez fisiológica, pero en condiciones aún no aptas para consumo. Después de $3 \mathrm{~d}$ de almacenamiento, se diferenciaron tres grupos en función del ablandamiento ocurrido en ese periodo. En el primer grupo formado por los frutos con 1MCP y 1-MCP+etefón, no se detectaron reducciones significativas en la firmeza, lo cual indicó que el ablandamiento en papaya es una respuesta inducida por la percepción de etileno y que la aplicación de etefón posterior al tratamiento con 1-MCP no revierte el efecto del inhibidor. Los frutos testigo formaron el segundo grupo, el cual se caracterizó por una pérdida de firmeza intermedia que alcanzó valores de $110 \mathrm{~N}$ a los $3 \mathrm{~d}$. El tercer grupo correspondiente a los frutos de los tratamientos etefón y etefón $+1-\mathrm{MCP}$, mostraron un rápido ablandamiento en respuesta al etefón ya que en $3 \mathrm{~d}$ la firmeza disminuyó a valores entre 30 y $48 \mathrm{~N}$.

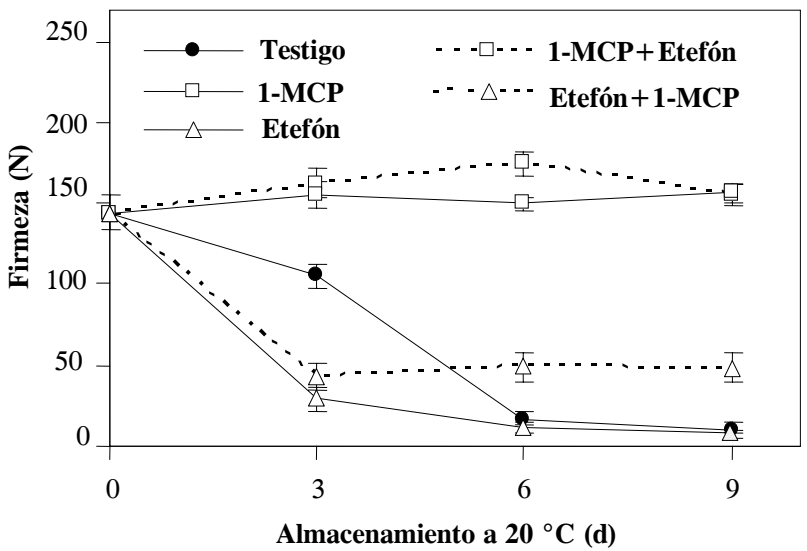

Figura 2. Firmeza (N) de papaya 'Maradol' tratada con 1-MCP, etefón, 1-MCP+etefón y etefón+1-MCP. La barra vertical representa el error estándar $(n=3)$.

El efecto del inhibidor e inductor de la maduración en frutos de papaya, se observó en la velocidad de ablandamiento de los frutos. La aplicación de 1-MCP bloqueó por completo el evento y los frutos mantuvieron la firmeza inicial de $144 \mathrm{~N}$, aún después de $9 \mathrm{~d}$ de almacenamiento. En cambio, los frutos tratados con etefón disminuyeron drásti- camente su firmeza a los $3 \mathrm{~d}$ del almacenamiento y perdieron $80 \%$ del valor inicial, aunque a los $6 \mathrm{~d}$ la firmeza no presentó diferencias significativas con respecto al testigo. El tratamiento con etefón +1-MCP mostró la efectividad del 1-MCP para detener el ablandamiento extensivo de frutos inducido por etefón, mismos que mantuvieron un valor de $48 \mathrm{~N}$ entre los 3 y $9 \mathrm{~d}$ de almacenamiento.

Se ha demostrado que el retraso en la velocidad de ablandamiento es una de las principales ventajas que ofrece el 1-MCP (Golding et al., 1998; Hofman et al., 2001), debido a su efecto inhibidor en la producción de hidrolasas de la pared celular las cuales se estimulan con la percepción de etileno (Manenoi y Paull, 2007; Thumdee et al., 2007). En el presente estudio, la aplicación de 1-MCP bloqueó la síntesis de etileno y el ablandamiento de los frutos (Figura 1B y 2). El efecto marcado del 1-MCP en papaya puede ser debido a que este fruto acumula lentamente nuevos receptores de etileno disponibles para la acción de la hormona y para la restauración de los eventos de la maduración (Hofman et al., 2001).

Según Jiang et al. (1999), el uso combinado de 1-MCP y etileno tuvo un gran potencial tecnológico como estrategia de manipulación de la maduración de plátano. En papaya 'Maradol' la aplicación de 1-MCP cuando el fruto no ha desarrollado la madurez comercial presenta severas limitaciones, pero la combinación etileno+1-MCP puede ser una estrategia efectiva para inducir atributos de calidad y detener la maduración extensiva de los frutos. Además, es posible optimizar el uso del 1-MCP en estudios adicionales que consideren variaciones en tiempos de exposición y en dosis del inhibidor, así como el estado de madurez óptimo de los frutos.

\section{Color interno y externo}

Al momento del corte, la pulpa de los frutos de papaya presentaron valores de L 45 , Hue $37^{\circ}$ y croma 26 , que caracteriza el color interno de la madurez comestible. En estos frutos los tratamientos y los tiempos de almacenamiento tuvieron efectos menores, que se consideraron insignificantes (datos no mostrados). La presencia de matices naranja-rojizo en la pulpa de los frutos cuando el color en cáscara estaba parcialmente desarrollado, indicó que la maduración en el fruto papaya progresó de la zona interna hacia la epidermis, tal como reportaron Paull et al. (1997).

El desarrollo del color externo mostró diferencias significativas durante el almacenamiento y entre tratamientos (Figura 3). El valor de L incrementó del día 0 al 3, sobre todo en los tratamientos testigo, etefón y etefón $+1-\mathrm{MCP}$, en comparación con el aumento observado en los frutos de 1-MCP y 1-MCP+etefón. Después de 3 d, la L disminuyó 
en todos los casos (Figura 3A). El cambio en el matiz externo se asoció con el perfil de firmeza. Al día 0 el matiz fue de 96.6, y a los 9 d de almacenamiento se diferenciaron tres grupos de desarrollo de color: los frutos testigo y los tratados con etefón disminuyeron el matiz a $65.3^{\circ}$; los frutos tratados con etefón +1 -MCP mostraron un matiz intermedio de $70.4^{\circ} ; \mathrm{y}$ los frutos de los tratamientos 1-MCP y $1-\mathrm{MCP}+$ etefón tuvieron un matiz de 80.2 y $79^{\circ}$, respectivamente (Figura 3B). Esta relación fue similar a la reportada por Urbano et al. (2004), quienes utilizaron el matiz como predictor del índice de madurez y como indicador de la actividad fotosintética en papaya 'Golden'.
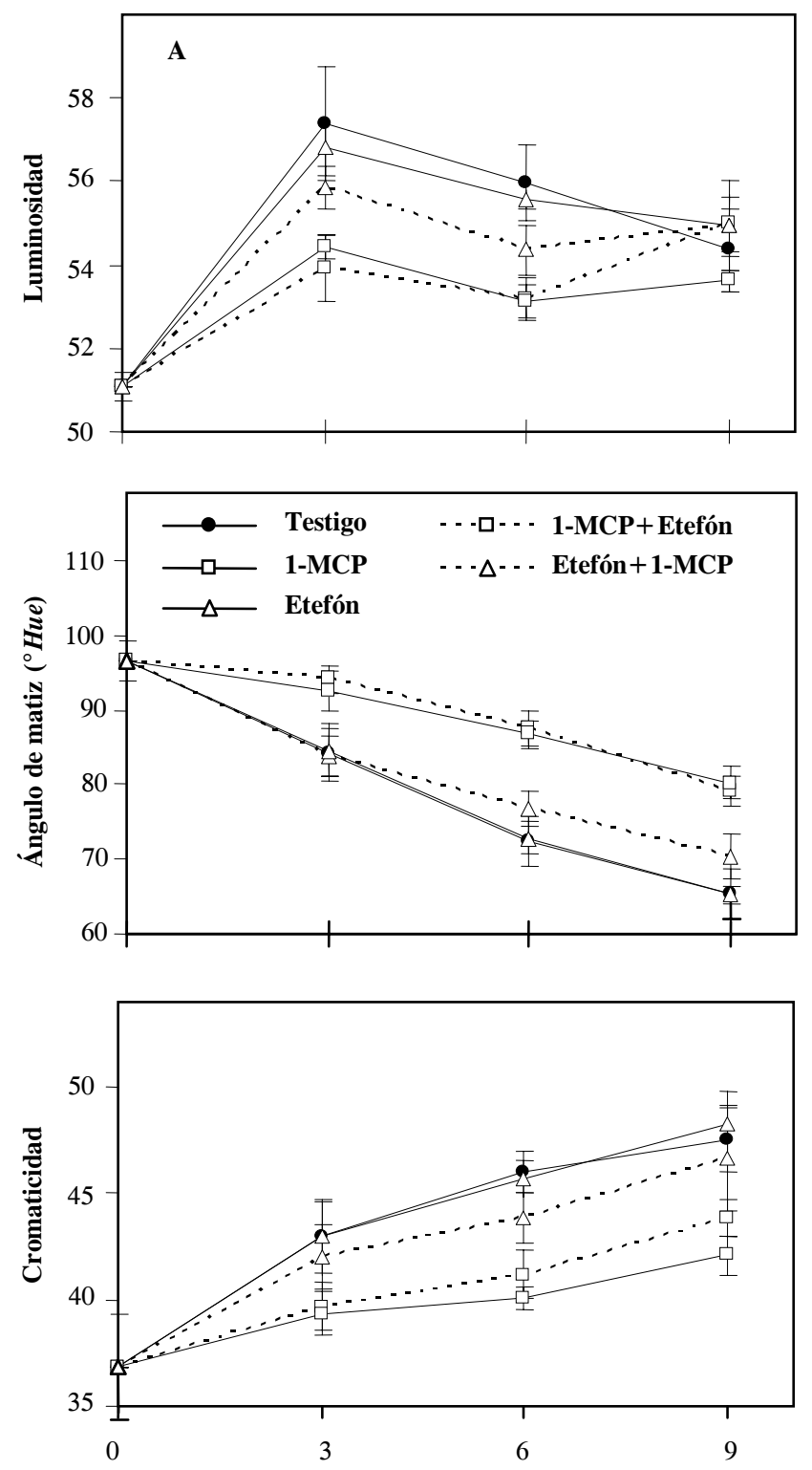

Figura 3. Color externo de papaya 'Maradol' tratada con 1-MCP, etefón, 1-MCP+ etefón y etefón +1-MCP. A) Luminosidad. B) Matiz. C) Cromaticidad. La barra vertical representa el error estándar $(n=$ 5).
El etefón indujo el desarrollo de color pero no fue efectivo en revertir el efecto del 1-MCP. La saturación de color medido con la variable croma fue significativamente menor en los frutos de los tratamientos 1-MCP y 1$\mathrm{MCP}+$ etefón (Figura 3C). El croma inicial fue de 38, y a los $3 \mathrm{~d}$ de almacenamiento los frutos tratados con etefón presentaron un croma similar al testigo y significativamente mayor a los frutos de los tratamientos 1-MCP y 1MCP+etefón (43 vs. 39.3 y 39.6, respectivamente).

El 1-MCP redujo el desarrollo de color en papaya 'Maradol' (Figura 4), lo que sugiere que la biosíntesis de carotenoides y la degradación de clorofilas son eventos regulados parcialmente por el etileno (Lelièvre et al., 1997). En melón (Cucumis melo L.) la supresión de la síntesis de etileno no inhibe la acumulación de carotenoides (Ayub et al., 1996); contrariamente, en tomate (Lycopersicon esculentum) la inhibición de etileno suprime la acumulación de licopeno (Hoeberichts et al., 2002).

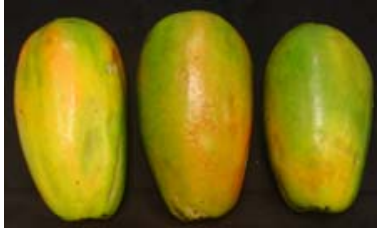

Testigo, $0 \mathrm{~d}$

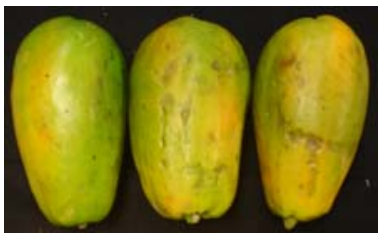

1-MCP, 6 d

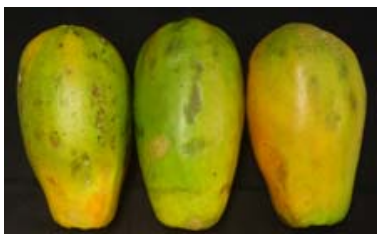

1-MCP+Etefón, $6 \mathrm{~d}$

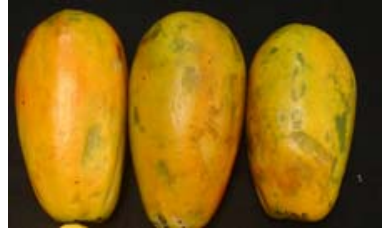

Testigo, $6 \mathrm{~d}$

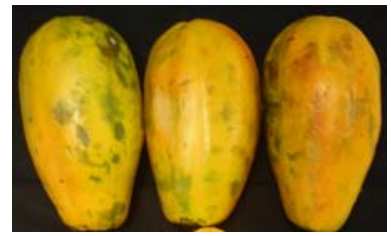

Etefón, $6 \mathrm{~d}$

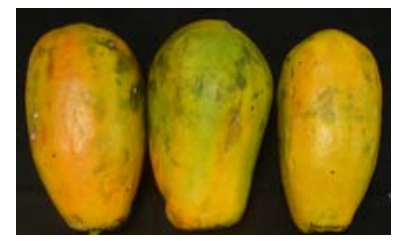

Etefón + 1-MCP, 6 d
Figura 4. Cambios en apariencia externa durante el almacenamiento a $20{ }^{\circ} \mathrm{C}$ de frutos de papaya 'Maradol' tratados con 1-MCP, Etefón, 1-MCP+Etefón y Etefón+1-MCP.

\section{pH, acidez titulable y sólidos solubles totales}

Los frutos de papaya presentan poca variación en el contenido de acidez titulable (AT) y de sólidos solubles totales (SST) durante su maduración (Gomez et al., 2002). En este estudio los frutos de los tratamientos testigo y etefón no presentaron cambios significativos en $\mathrm{pH}$ y AT 
durante el almacenamiento, al mantener un $\mathrm{pH}$ de 5.35 a 5.5 unidades y una AT de 0.09 a $0.1 \%$. Valores similares de AT fueron reportados para papaya 'Solo' durante su maduración (Cano et al., 1994). Los frutos tratados con 1MCP y 1-MCP+etefón aumentaron su pH a 5.9 a los 6 d de almacenamiento, y disminuyeron su AT a valores de 0.06 a $0.07 \%$ (Figura 5A y 5B). Estos resultados muestran que durante el almacenamiento, los frutos tratados con 1-MCP y 1-MCP + etefón, consumieron los ácidos orgánicos con el consecuente incremento en $\mathrm{pH}$; en cambio, los frutos de los tratamientos testigo, etefón y etefón $+1-\mathrm{MCP}$, no modificaron significativamente estas variables, lo que sugiere que estos frutos utilizaron otras fuentes de energía durante la maduración.

El contenido de SST no presentó diferencias significativas entre tratamientos, y durante el almacenamiento sólo se observó un aumento significativo del día 0 (10 ${ }^{\circ}$ Brix $)$ al día 3 (12.4 ${ }^{\circ}$ Brix) en los frutos testigo (datos no mostrados). Se registró una alta variabilidad en los datos de los días siguientes en todos los tratamientos, con valores promedio entre 10.5 y $12.5^{\circ}$ Brix. En un estudio con papaya 'Solo' se reportó que durante la maduración del fruto aumentan los contenidos de glucosa, fructosa y sacarosa de 38.6 a $48.6 \mathrm{mg} \mathrm{g}^{-1}$ de peso fresco, atribuible a una acumulación de sacarosa y al incremento en la actividad de sacarosa sintasa y sacarosa fosfato sintasa (Gomez et al., 2002); estos autores mencionan que debido a la escasa presencia de almidón en el fruto $(0.06 \%)$ como precursor de sacarosa, como fuente alternativa propusieron a la galactosa derivada de la hidrólisis de la pared celular.

\section{CONCLUSIONES}

El uso de 1-MCP o 1-MCP+etefón fue efectivo para reducir la velocidad de maduración de los frutos de papaya 'Maradol', pero inhibió el ablandamiento de manera irreversible. El tratamiento con etefón aceleró la maduración y los frutos alcanzaron los atributos de consumo a $3 \mathrm{~d}$ de la aplicación. La combinación etefón +1-MCP fue una estrategia efectiva para inducir la maduración sin ablandamiento extensivo de frutos, lo que permitió extender la vida útil de papaya 'Maradol'. Es posible optimizar el uso de 1-MCP mediante estudios adicionales en los que se varíen los tiempos de exposición, dosis y estado de madurez de los frutos.

\section{AGRADECIMIENTOS}

Al financiamiento UC Mexus-CONACyT, al apoyo técnico de Laura A. Contreras Angulo, Rosalba Contreras Martínez, Rosabel Vélez de la R., Manuel Báez Sañudo y Ana Rosa Mancillas.
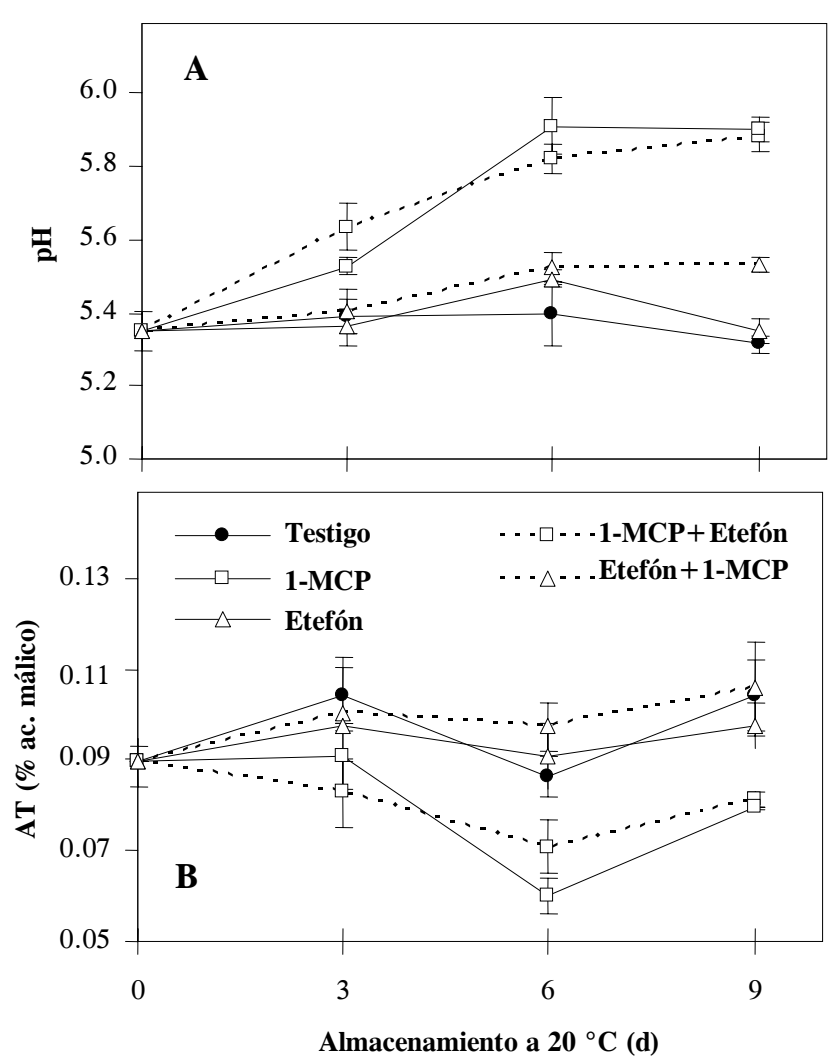

Figura 5. Variables de calidad química de papaya 'Maradol' tratada con 1-MCP, etefón, 1-MCP+etefón y etefón+1-MCP. A) pH. B) Acidez titulable expresada en \% de ácido málico. La barra vertical representa el error estándar $(n=3)$.

\section{BIBLIOGRAFÍA}

AOAC (1998) Official Methods of Analysis. 16th ed. S William (ed). Published by the Association of Official Analytical Chemists. Washington, D.C. CD-ROM.

Ayub R, M Guis, M Ben-Amor, I Gillot, J Roustan, A Latché, M Bouzayen, J Pech (1996) Expression of ACC oxidase antisense gene inhibits ripening of cantaloupe melon fruits. Nature Biotechnol. 14:862-866.

Báez M A, J Siller, B Heredia, E Araiza, R García, M D Muy (1997) Fisiología poscosecha de frutos de chicozapote (Achras sapota L.) durante condiciones de mercadeo. Proc. Interamerican Soc. Trop. Hort. 41:209-214.

Blankenship S M, J M Dole (2003) 1-Methylcyclopropene: a review. Postharv. Biol. Technol. 28:1-25.

Bourne M C (1980) Texture evaluation of horticultural crops. HortScience 15:51-57.

Cano M P, E Torija, M A Marín, M Cámara (1994) A simple ionexchange chromatographic determination of non-volatile organic acids in some Spanish exotic fruits. Zeitschrift Fur LebensmittelUntersuchung Und-Forschung 199:214-218.

Chandrika G U, E Jansz, S Nalinie, N Warnasuriya (2003) Carotenoids in yellow- and red-fleshed papaya (Carica papaya L). J. Sci. Food Agric. 83:1279-1282.

Golding J B, D Shearer, S Wyllie, W McGlasson (1998) Application of $1-\mathrm{MCP}$ and propylene to identify ethylene-dependent ripening process in mature banana fruit. Postharv. Biol. Technol. 14:8798. 
Gomez M, F Lajolo, B Cordenunsi (2002) Evolution of soluble sugars during ripening of papaya fruit and its relation to sweet taste. J. Food Sci. 67:442-447.

Hoeberichts F, L Van Der Plas, E Woltering (2002) Ethylene perception is required for the expression of tomato ripening-related genes and associated physiological changes even at advanced stages of ripening. Postharv. Biol. Technol. 26:125-133.

Hofman P J, M Jobin-Decor, G F Meiburg, A J Macnish, D C Joyce (2001) Ripening and quality responses of avocado, custard apple, mango and papaya fruit to 1-methylcyclopropene. Austr. J. Exp. Agric. 41:567-572.

Inaba A, X Liu, N Yokotani, M Yamane, W J Lu, R Nakano, Y Kubo (2007) Differential feedback regulation of ethylene biosynthesis in pulp and peel tissues of banana fruit. J. Exp. Bot. 58:1047-1057.

Jiang Y M, D C Joyce, A J Macnish (1999) Responses of banana fruit to treatment with 1-methylcyclopropene. Plant Growth Reg. 28:77-82.

Lelièvre J M, A Latché, B Jones, M Bouzayen, J Pech (1997) Ethylene and fruit ripening. Physiol. Plant. 101:727-739.

Manenoi A, R Paull (2007) Papaya fruit softening, endoxylanase gene expression, protein and activity. Physiol. Plant. 131:470-480.
Paull R E, W Nishijima, M Reyes, C Cavaletto (1997) Postharvest handling and losses during marketing of papaya (Carica papaya L.). Postharv. Biol. Technol. 11:165-179.

Paull R E, K Gross, Y Quiu (1999) Changes in papaya cell walls during fruit ripening. Postharv. Biol. Technol. 16:79-89.

Pino J A, K Almora, R Marbot (2003) Volatile components of papaya (Carica papaya L., Maradol variety) fruit. Flavour and Fragrance J. 18:492-496.

Quintana M E G, R E Paull (1993) Mechanical injury during postharvest handling of 'Solo' papaya fruit. J. Am. Soc. Hort. Sci. 118:618-622.

SAGARPA (2006) Anuario Estadístico de la Producción Agrícola. En línea [http://www.siap.gob.mx] (Fecha de consulta: Junio, 2007)

Thumdee S, A Manenoi, R E Paull (2007) Activity of papaya fruit hydrolases during natural softening and modified softening. Acta Hort. 740:317-322.

Urbano B I, R Vasconcelos, M Azzolini, A P Jacomino, E Caruso (2004) Chlorophyll fluorescence as a tool to evaluate the ripening of 'Golden' papaya fruit. Postharv. Biol. Technol. 33:163173 